\title{
The Goodness-of-fit of the Fractal Dimension as a Diagnostic Factor in Breast Cancer
}

\author{
Sotirios Maipas ${ }^{1}$, Afroditi Nonni ${ }^{1}$, Ekaterini Politi ${ }^{1}$, Helen Sarlanis ${ }^{1}$, Nikolaos G. Kavantzas ${ }^{1}$ \\ 1. Pathology, School of Medicine, National and Kapodistrian University of Athens, Athens, GRC
}

Corresponding author: Sotirios Maipas, sotgmaip@gmail.com

\begin{abstract}
A large number of studies have found that the fractal dimension increases with the progression towards pathological or more pathological states, but there are also studies that have demonstrated the opposite relationship. In this study, we calculate the nuclear box-counting fractal dimension of 109 malignant, 113 benign, and 80 normal isolated breast cells in order to investigate its possible diagnostic importance. We computed the fractal dimension and its goodness-of-fit (i.e., the r-squared value that describes how well the regression line fits the set of the measurements) for two different sets of box size lengths. The statistical analysis did not confirm an important diagnostic potential of the nuclear fractal dimension of isolated breast cells. However, the goodness-of-fit did display a diagnostic potential. The r-squared value may be able to serve as a complementary diagnostic parameter.
\end{abstract}

Categories: Pathology, Oncology, Other

Keywords: fractal dimension, box-counting dimension, goodness-of-fit, breast cancer, cancer diagnosis

\section{Introduction}

Fractal geometry, introduced by the Polish-born French-American mathematician, Benoit B. Mandelbrot, in the 70's, provides us with the necessary geometrical tools to describe the irregular shapes found in nature [12]. Fractal dimension is a term of fractal geometry that can be defined as a unitless measure of morphological complexity [3-5]. The box-counting dimension is the most popular and easiest to calculate the fractal dimension, and it can be computed for both fractal and non-fractal objects [3-4, 6-7]. Fractal analysis has been applied in the study of various malignant tumors, such as breast cancer, endometrial carcinoma, and oral and laryngeal cancer [4, 8-14]. A large number of studies have found that the fractal dimension increases with the increase of malignancy, but there are also studies that have demonstrated the opposite relationship [4, 10, 15-16]. Herein, we calculate the nuclear box-counting fractal dimension of isolated malignant, benign, and normal breast cells in order to investigate its possible diagnostic importance.

Received 11/02/2018

Review began 11/14/2018 Review ended 11/20/2018 Published 11/24/2018

๑) Copyright 2018

Maipas et al. This is an open access article distributed under the terms of the Creative Commons Attribution License CC-BY 3.0., which permits unrestricted use, distribution, and reproduction in any medium, provided the original author and source are credited.

\section{Materials And Methods}

Three hundred and two cells were selected from 155 electron microscopy images (40x) of breast smears. One hundred and nine cells were malignant, 113 cells were benign, and 80 cells were normal. Each image was introduced into Mathematica 10.4 (Wolfram Research, Champaign, IL) in order to be transformed by built-in Mathematica functions into binary-outline figures, as can be seen in Figures 1-3, where the red arrows indicate the selected nuclei.
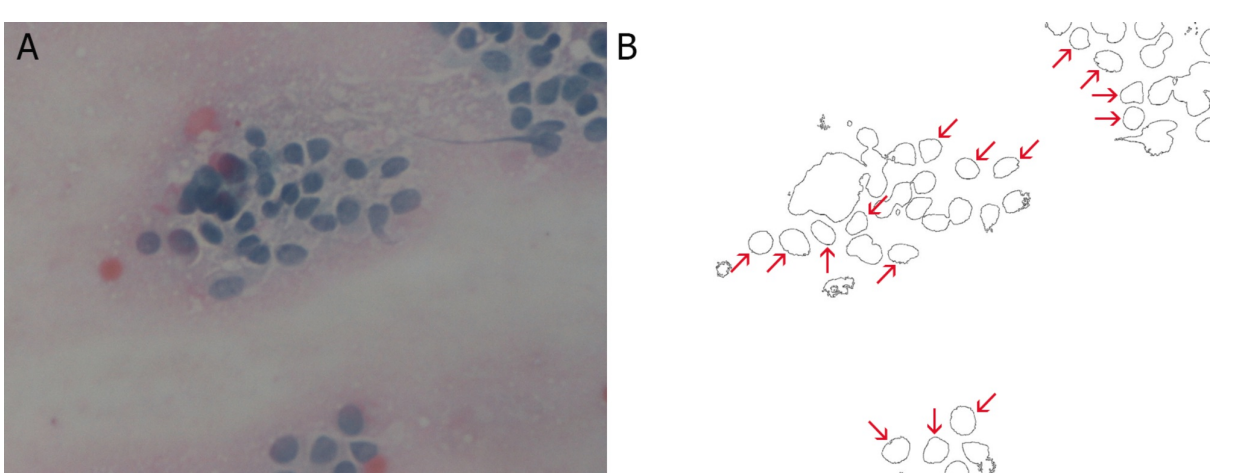

FIGURE 1: Breast smear of malignant cells from a case of breast adenocarcinoma at $40 x$ magnification $(A)$ and the same image after the necessary transformations (B) 


\section{Cureus}
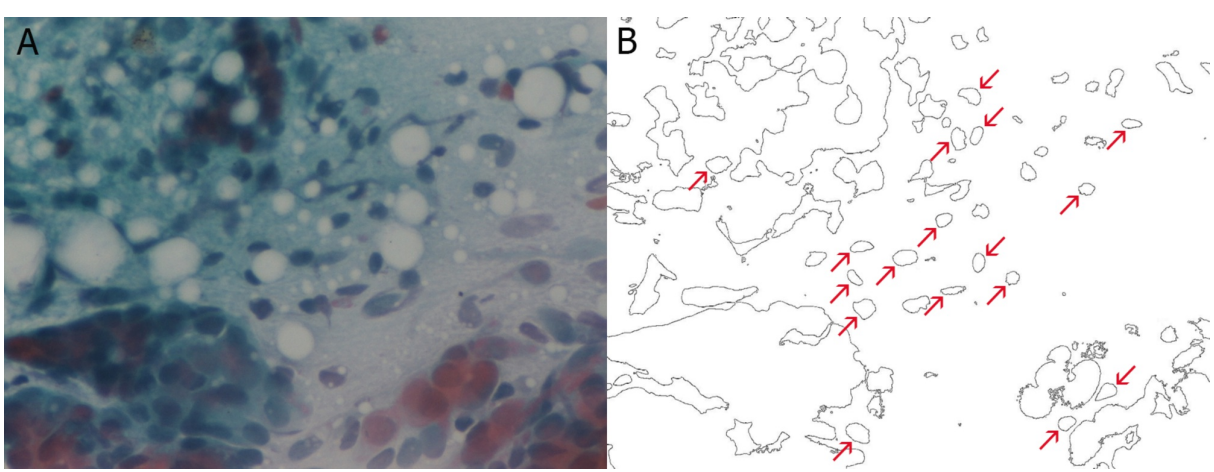

FIGURE 2: Breast smear of benign cells from a case of fibroepithelial tumor at $40 x$ magnification $(A)$ and the same image after the necessary transformations (B)

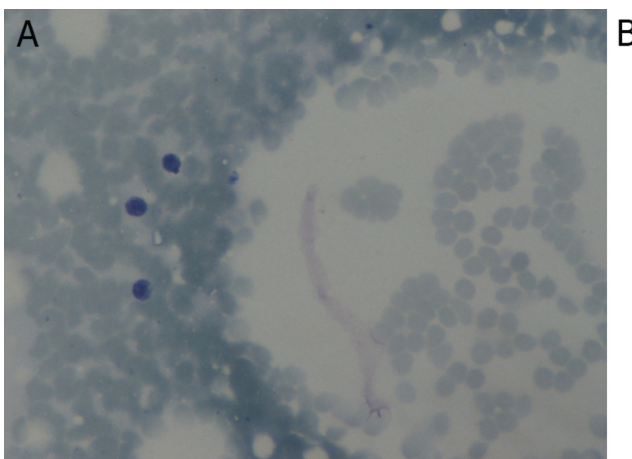

B

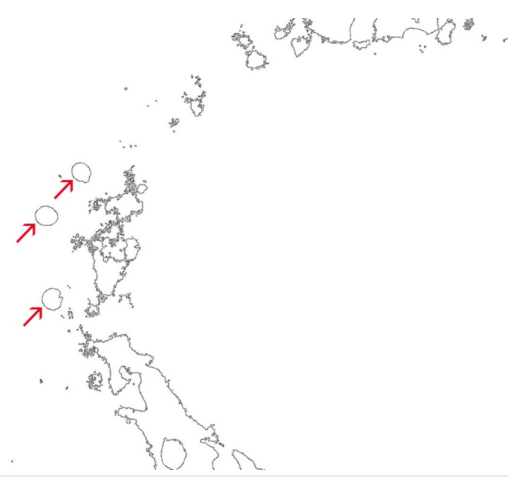

FIGURE 3: Breast smear of normal epithelial cells at 40x magnification (A) and the same image after the necessary transformations (B)

The nuclear box-counting fractal dimension of the selected nuclei and its goodness-of-fit were computed using the open-source plug-in, FracLac, of the ImageJ software (United States National Institute of Health). FracLac covered each nucleus with consecutive square boxes of various side lengths and counted the smallest number of boxes of each size required to cover each nuclear contour. The box-counting fractal dimension was equal to the slope of the regression line of the log-log plot of the scale (scale = box size/image size) and of the number of the boxes $[3,17]$. The box size lengths were chosen to be $3,5,7,9,11,13,15,17$, and 19 pixels (Case A), and also 1 to 20 pixels (Case B). The goodness-of-fit of the regression line (i.e., the rsquared value that describes how well the regression line fits the set of the measurements) was also computed by FracLac. All the obtained data were analyzed using the Statistical Package for Social Sciences (SPSS) Statistics, version 20 (IBM SPSS Statistics, Armonk, NY). The statistical analysis included the oneway analysis of variance (ANOVA) and post hoc tests.

The protocol of the study was approved by the Bioethics Committee of the National and Kapodistrian University of Athens, Greece. Furthermore, images were already archived into folders which did not include personal information. Given the fact that we analyzed cells from unknown human subjects, there was no ethical conflict.

\section{Results}

For Case A, the mean fractal dimensions of malignant, benign, and normal cells were $1.123648 \pm 0.0589598$, $1.146548 \pm 0.0706589$, and $1.110653 \pm 0.0543317$, respectively. Statistical analysis revealed a significant difference in the mean fractal dimension of benign and normal cells.

For Case B, the mean fractal dimensions of malignant, benign, and normal cells were $1.072341 \pm 0.0400440$, $1.086766 \pm 0.0448004$, and $1.072745 \pm 0.0881955$, respectively. Contrary to the previous case, the current statistical analysis did not show any significant difference between the three cell groups.

Regarding the goodness-of-fit (r-squared value) for Case A, the mean values were $0.991072 \pm 0.0068385$ for malignant cells, $0.983985 \pm 0.0134711$ for benign cells, and $0.986498 \pm 0.110298$ for normal cells. The post hoc tests revealed a significant difference in the mean values between malignant and benign cells. 
For Case B, the mean r-squared values were $0.992738 \pm 0.0042910$ for malignant cells, $0.987791 \pm 0.0070012$ for benign cells, and $0.989768 \pm 0.0065955$ for normal cells. Post hoc tests revealed significant differences in the mean values between malignant and benign cells, as well as between malignant and normal cells.

In both cases, the statistical analysis revealed that the goodness-of-fit of the fractal dimension may display diagnostic potential, as it was able to distinguish malignant from benign cells.

\section{Discussion}

It has been demonstrated that fractal properties are altered with development, growth, aging, and also in disease [18]. However, it is difficult to establish a general rule about the behavior of the fractal dimension in regard to progression towards pathological (or more pathological) states.

Our study demonstrated that the goodness-of-fit of the fractal dimension, known for its prognostic potential [19-21], may serve as a complementary diagnostic parameter. We also confirmed the fact that the box-counting method for the calculation of the fractal dimension is box-size sensitive [22].

An important limitation for the calculation of nuclear box-counting fractal dimensions of isolated cells arises from the overlapping nuclei in smears which decrease the level of automatization of the procedure or make many images inappropriate for the calculation of nuclear fractal dimensions. Moreover, if the experimental dataset includes lobular breast cancer cells (as in our study), the study of morphological characteristics requires more attention because lobular malignant cells may have small nuclei and, therefore, sometimes may not be easily distinguishable from non-malignant cells [23].

Moreover, the digital camera specifications, the quality (e.g., resolution, noise) of the acquired images, the quality of the segmentation (procedure, aiming at separating the regions of interest from the rest of the image, which depends on the thresholding method), and the software tools affect the fractal dimension values [24-26]. The existence of noise impedes the full automatization of the process because, for instance, final (binary) images may have unnecessary objects that must be removed by the user before the calculation of the fractal dimension. It should also be added that the method of outlining in the relevant literature is not always automatic, as outlining has been performed with the help of pointer or by hand [11, 14, 27].

There is no doubt that more extensive research needs to be undertaken regarding the biomedical application of the toolbox of fractal geometry, aiming at increasing its efficacy and its reliability. Given the continuous technological advances in imaging technologies, such as better cameras and software, we expect that fractal analysis is going to be applied more widely.

\section{Conclusions}

Our study used a large number of breast cells. We did not confirm an important diagnostic potential of the nuclear fractal dimension of isolated breast cells. However, the goodness-of-fit did display a diagnostic importance. The r-squared value may be able to serve as a complementary diagnostic parameter.

\section{Additional Information \\ Disclosures}

Human subjects: Consent was obtained by all participants in this study. Animal subjects: All authors have confirmed that this study did not involve animal subjects or tissue. Conflicts of interest: In compliance with the ICMJE uniform disclosure form, all authors declare the following: Payment/services info: All authors have declared that no financial support was received from any organization for the submitted work. Financial relationships: All authors have declared that they have no financial relationships at present or within the previous three years with any organizations that might have an interest in the submitted work. Other relationships: All authors have declared that there are no other relationships or activities that could appear to have influenced the submitted work.

\section{References}

1. Weibel ER: Mandelbrot's fractals and the geometry of life: a tribute to Benoît Mandelbrot on his 80th birthday. Fractals in Biology and Medicine. Losa GA, Merlini D, Nonnenmacher TF, Weibel ER (ed): Birkhäuser Verlag, Basel; 2005. 4:3-16. 10.1007/3-7643-7412-8 1

2. Mandelbrot B: A geometry able to include mountains and clouds . The Colours Of Infinity. Lesmoir-Gordon N (ed): Springer, London; 2010. 38-57. 10.1007/978-1-84996-486-9 3

3. Karperien AL, Jelinek HF: Box-counting fractal analysis: a primer for the clinician. The Fractal Geometry Of The Brain. Di Ieva A (ed): Springer, New York; 2016. 13-43. 10.1007/978-1-4939-3995-4_2

4. Yinti SR, Srikant N, Boaz K, Lewis AJ, Ashokkumar PJ, Kapila SN: Nuclear fractal dimensions as a tool for prognostication of oral squamous cell carcinoma. J Clin Diagn Res. 2015, 9:EC21-25. 10.7860/JCDR/2015/12931.6837

5. Losa GA, Ristanović D, Ristanović D, Zaletel I, Beltraminelli S: From fractal geometry to fractal analysis . Appl Math. 2016, 7:346-54. 10.4236/am.2016.74032 
6. Peitgen HO, Jürgens H, Saupe D: Length, area and dimension: measuring complexity and scaling properties. Chaos and Fractals: New Frontiers Of Science. Peitgen HO, Jürgens H, Saupe D (ed): Springer, New York; 2004. 173-214. 10.1007/0-387-21823-8_5

7. Annadhason A: Methods of fractal dimension computation . IRACST - IJCSITS. 2012, 2:166-69. Accessed: October 5, 2018: http://www.ijcsits.org/papers/Vol2no12012/29vol2no1.pdf.

8. Delides A, Panayiotides I, Alegakis A, et al.: Fractal dimension as a prognostic factor for laryngeal carcinoma. Anticancer Res. 2005, 25:2141-44.

9. Dey P, Mohanty SK: Fractal dimensions of breast lesions on cytology smears . Diagn Cytopathol. 2003, 29:8586. 10.1002/dc.10324

10. Ohri S, Dey P, Nijhawan R: Fractal dimension in aspiration cytology smears of breast and cervical lesions . Anal Quant Cytol Histol. 2004, 26:109-12.

11. Goutzanis L, Pavlopoulos PM, Papadogeorgakis N: Fractal analysis in the study of oral cancer . Aust Asian J Cancer. 2012, 11:5-12.

12. Bikou O, Delides A, Drougou A, Nonni A, Patsouris E, Pavlakis K: Fractal dimension as a diagnostic tool of complex endometrial hyperplasia and well-differentiated endometrioid carcinoma. In Vivo. 2016, 30:681-90.

13. Chan A, Tuszynski JA: Automatic prediction of tumour malignancy in breast cancer with fractal dimension . R Soc Open Sci. 2016, 3:160558. 10.1098/rsos.160558

14. Dey P, Rajesh L: Fractal dimension in endometrial carcinoma . Anal Quant Cytol Histol. 2004, 26:113-16.

15. Fiz JA, Monte-Moreno E, Andreo F, et al.: Fractal dimension analysis of malignant and benign endobronchial ultrasound nodes. BMC Med Imaging. 2014, 14:22. 10.1186/1471-2342-14-22

16. Stehlík M, Giebel SM, Prostakova J, Schenk JP: Statistical inference on fractals for cancer risk assessment . Pak J Statist. 2014, 30:439-54. October 15, 2018

17. FracLac Advanced User's Manual . (2005). Accessed: November 13, 2018 : http://imagej.nih.gov/ij/plugins/fraclac/fraclac-manual.pdf.

18. Thamrin C, Stern G, Frey U: Fractals for physicians . Paediatr Respir Rev. 2010, 11:123-31. 10.1016/j.prrv.2010.02.001

19. Metze K, Lorand-Metze I, Leite NJ, Adam RL: Goodness-of-fit of the fractal dimension as a prognostic factor. Cell Oncol. 2009, 31:503-504. 10.3233/CLO-2009-0505

20. Ferro DP, Falconi MA, Adam RL, et al.: Fractal characteristics of May-Grünwald-Giemsa stained chromatin are independent prognostic factors for survival in multiple myeloma. PLoS One. 2011, 6:e20706. 10.1371/journal.pone.0020706

21. Metze K: Fractal dimension of chromatin: potential molecular diagnostic applications for cancer prognosis . Expert Rev Mol Diagn. 2013, 13:719-35. 10.1586/14737159.2013.828889

22. Pruess SA: Some remarks on the numerical estimation of fractal dimension . Fractals In The Earth Sciences. Barton CC, La Pointe PR (ed): Springer, Boston; 1995. 65-75. 10.1007/978-1-4899-1397-5_3

23. McCart Reed AE, Kutasovic JR, Lakhani SR, Simpson PT: Invasive lobular carcinoma of the breast: morphology, biomarkers and 'omics. Breast Cancer Res. 2015, 17:12. 10.1186/s13058-015-0519-X

24. Kiselev VG, Hahn KR, Auer DP: Is the brain cortex a fractal? . Neuroimage. 2003, 20:1765-74. 10.1016/S10538119(03)00380-X

25. Tavakol ME, Lucas C, Sadri S, Ng EYK: Analysis of breast thermography using fractal dimension to establish possible difference between malignant and benign patterns. J Healthc Eng. 2010, 1:27-43. 10.1260/20402295.1.1.27

26. Hadzieva E, Bogatinoska DC, Petroski R, Shuminoska M, Gjergjeska L, Karadimce A, Trajkova V: Is the fractal dimension of the contour-lines a reliable tool for classification of medical images?. MATEC Web of Conferences. 2016, 76:05002. 10.1051/matecconf/20167605002

27. Rangayyan RM, Nguyen TM: Fractal analysis of contours of breast masses in mammograms . J Digit Imaging. 2007, 20:223-37. 10.1007/s10278-006-0860-9 